\title{
Solvent-screening and co-crystal screening for drug development with COSMO-RS
}

\author{
A Klamt
}

\section{From 7th German Conference on Chemoinformatics: 25 ClC-Workshop}

Goslar, Germany. 6-8 November 2011

Bringing active pharmaceutical or agrochemical ingredients (APIs) in solution often is the most demanding step in pharmaceutical and agrochemical development. The COSMO-RS method, which has been originally developed by the author during his 12 years at Bayer, is a unique combination of quantum chemical information and liquid phase thermodynamics and currently is proven to be the most accurate method for predicting the free energy of molecules in solution. Based on COSMORS theory the COSMOtherm suite of software tools is able to address a broad range of important aspects of solubilization and thus is an ideally suited toolset for rational solubilization development:

- Solvent screening, including mixtures and variable temperatures

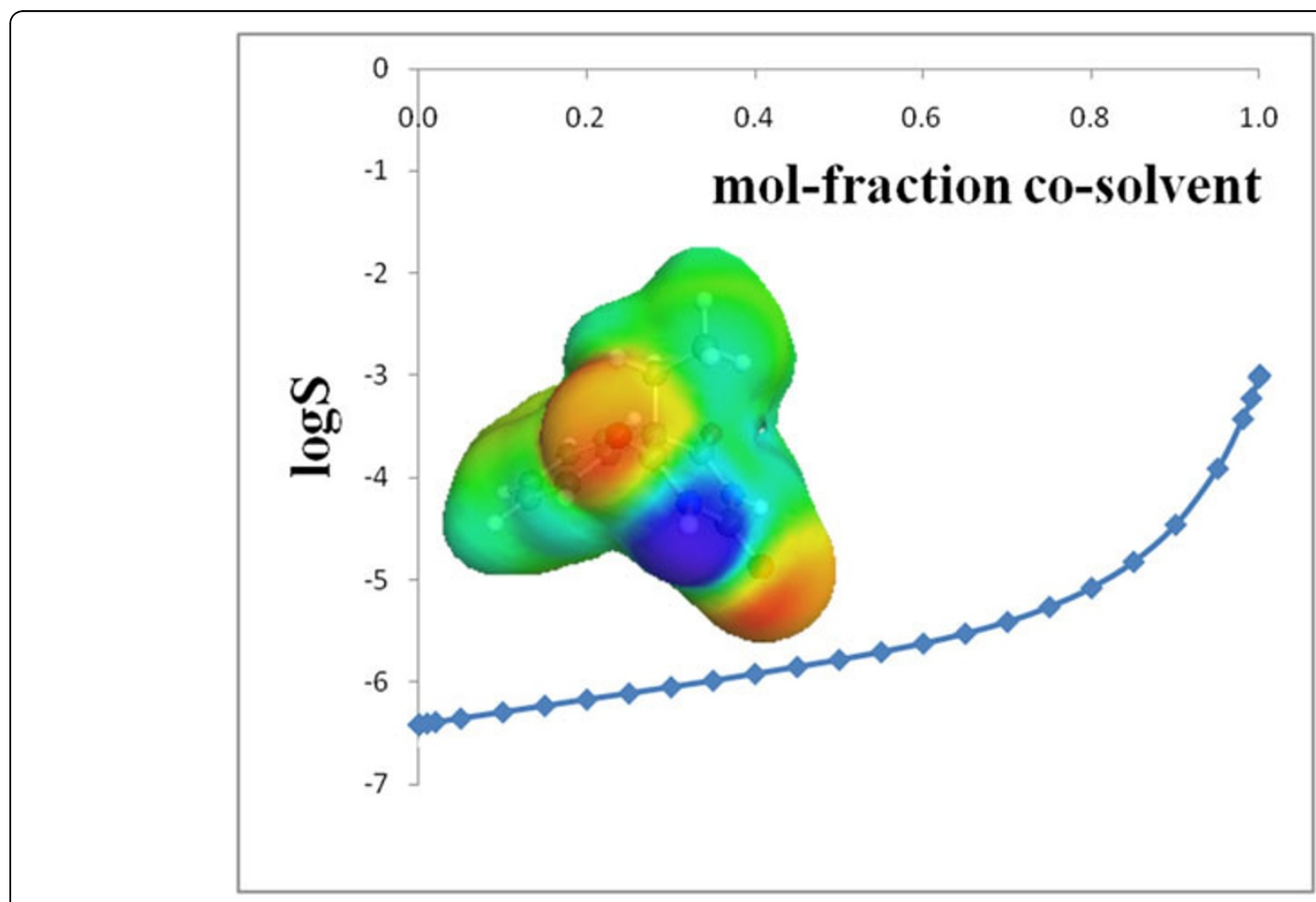

Figure 1

Correspondence: klamt@cosmologic.de

COSMOlogic GmbH\&CoKG, Leverkusen and Inst. of Phys. and Theoretical

Chemistry, University of Regensburg, Germany 
- $\log \mathrm{P}, \log \mathrm{D}$ and $\mathrm{pK}_{\mathrm{a}}$ prediction, general multi-phase distribution

- conformational preference and tautomer trends in solution

- Co-crystal screening based on mixing enthalpy

- solubility in micellar systems

- solvent-dependent free energy of crystal faces

Published: 1 May 2012

doi:10.1186/1758-2946-4-S1-014

Cite this article as: Klamt: Solvent-screening and co-crystal screening for drug development with COSMO-RS. Journal of Cheminformatics 2012 4(Suppl 1):O14.

\section{Publish with ChemistryCentral and every scientist can read your work free of charge \\ "Open access provides opportunities to our colleagues in other parts of the globe, by allowing anyone to view the content free of charge." W. Jeffery Hurst, The Hershey Company. \\ - available free of charge to the entire scientific community \\ - peer reviewed and published immediately upon acceptance \\ - cited in PubMed and archived on PubMed Central \\ - yours - you keep the copyright \\ Submit your manuscript here:

